\title{
REVALUASI SPESIFIKASI KEBUTUHAN PERANGKAT LUNAK SISTEM INFORMASI AKADEMIK TERINTEGRASI
}

\author{
Agatha Grace Maharani Sarwono ${ }^{1)}$, Yudhi Kurniawan ${ }^{2)}$ \\ 1) 2) Sistem Informasi Universitas Machung, Villa Puncak Tidar N-1 Malang \\ email:321510001@student.machung.ac.id ${ }^{l}$, yudhi.kurniawan@machung.ac.id ${ }^{2}$
}

\begin{abstract}
Abstraksi
Universitas Ma Chung adalah salah satu univesitas yang telah menerapkan dan memanfaatkan teknologi, yaitu dibuktikan adanya sistem informasi akademik macsys 1 dan macsys2. Seiring dengan berkembangnya kebutuhan universitas yang semakin kompleks, pada tahun 2018 Unit Pelaksana Teknis Sistem Informasi (UPT SI) di Universitas Ma Chung telah merilis satu sistem baru yang terintegrasi antara sistem informasi bagian akademik dan non-akademik. Sistem terintegrasi yang sedang terus dibangun ini disebut macIS yaitu Ma Chung Integrated System. Berdasarkan proses pembangunan dan pengembangan sistem yang ada, Universitas Ma Chung belum memiliki dokumen spesifikasi kebutuhan perangkat lunak (SRS) baik untuk macsys1, macsys2 maupun macIS.Berdasarkan latar belakang yang ada, dapat disimpulkan yaitu bagaimana menyusun dokumen spesifikasi kebutuhan perangkat lunak untuk sistem informasi terintegrasi pada Universitas Ma Chung yang telah dibangun agar sistem yang ada sesuai dengan kebutuhan organisai dan kebutuhan pengembangan sistem selanjutnya.

Penyusunan dokumen dilakukan dengan menggunakan metode analisis kebutuhan berorientasi obyek. Analisis sistem berorientasi objek ini merupakan tahapan perantara untuk memetakan spesifikasi yang teridentifkasi sehingga kebutuhan sistem dapat lebih mudah diimplementasikan. Hal ini dilakukan dengan menganalisis proses bisnis yang sedang berjalan di Univeristas Ma Chung. Sedangkan untuk penulisan dokumen menggunakan standar internasional dan terbaru yaitu ISO/IEC/IEEE 29148-2011. Hasil akhir yang diperoleh adalah sebuah dokumen revaluasi spesifikasi kebutuhan perangkat lunak sesuai dengan kebutuhan organisai dan kebutuhan pengembangan sistem dengan standar dokumentasi internasional yaitu ISO/IEC/IEEE 29148-2011.
\end{abstract}

\section{Kata Kunci:}

Spesifikasi kebutuhan perangkat lunak (SRS), Sistem akademik, proses bisnis, Kebutuhan Sistem dan Pengguna.

\begin{abstract}
Ma Chung University is one of the universities that has approved and used technology, which is proven by the existence of macsys 1 and macsys 2 academic information systems. In 2018 the Technical Information System Implementation Unit (UPT SI) at Ma Chung University has released a new system that combines the academic and non-academic information systems. The integrated system being built is called MacIS, which is the Integrated System of Ma Chung.Based on the existing system development and development process, Ma Chung University does not yet have a software requirements specification document (SRS) for both macsys1, macsys 2 and macIS. Based on the study case, it can be concluded about how to compile a software requirements specification document for integrated information systems at Ma Chung University that fits the needs of the organization and system development needs. Document preparation is done using objectoriented needs analysis methods. This object-oriented system analysis is an integrated design to map identified specifications so that system requirements can be more easily implemented. This is done by analyzing the business processes that are running at Ma Chung University. Meanwhile to discuss documents using the latest international standards, namely ISO / IEC / IEEE 29148-2011.The final result obtained is a revaluation document specification of equipment requirements in accordance with organizational needs and system development needs with international certification standards, namely ISO / IEC / IEEE 29148-2011.
\end{abstract}

\section{Keywords:}

Software requirements specifications (SRS), Academic systems, Business processes, system requirements and users. 


\section{PENDAHULUAN}

Proses pengembangan perangkat lunak merupakan sesuatu hal yang tidak mudah, dibutuhkan kemampuan, pengetahuan dan teknologi lain yang mendukung. Pada proses pembangunan dan pengembangan sistem terdapat beberapa tahapan umum yaitu analisis, desain, coding, testing dan implementation. Tahapan-tahapan tersebut terdapat dalam banyak metode diantaranya adalah Waterfall model, V modeldan Agile methods, Incremental Process Model[1]. Hampir pada seluruh metode yang ada, tahapan pertama adalah kegiatan analisis, yaitu penguraian dari suatu sistem informasi yang utuh kedalam bagian-bagian komponennya dengan maksud untulk mengidentifikasikan dan mengevaluasi permasalahan-permasalahan, kesempatan-kesempatan, hambatan-hambatan yang terjadi dan kebutuhan yang diharapkan sehingga dapat diusulkan perbaikannya [2]. Kegiatan analisis ini memiliki tujuan untuk merancang sistem baru maupun menyempurnakan sistem yang sudah ada sebelumnya [3]. Analisis yang dilakukan adalah untuk mengetahui kebutuhan dari pengguna yang akan menggunakan sistem dan respon apa yang dilakukan oleh sistem untuk memenuhi dari kebutuhan pengguna tersebut. Sehingga pada tahapan analisis ini akan menghasilkan sebuah dokumen SRS (Software Requirements specifications).

Unit Pelaksana Teknis Sistem Informasi (UPT SI) Universitas Ma Chung telah membangun sebuah sistem informasi terintegrasi (macIS) yang mengolah data akademik dan non-akademik. MacIS ini adalah sebuah sistem besar yang di dalamnya terdiri dari banyak sistem dan beberapa sistem telah selesai dibangun dan digunakan oleh pihak yang berkepentingan. Namun dalam proses pembangunan sistem khususnya pada tahap analisis, UPT SI belum memiliki dokumen SRS sebagai bentuk dokumentasi kegiatan. Oleh karena hal tersebut, penelitian ini dilakukan untuk menghasilkan sebuah dokumen SRS yang mendokumentasikan kebutuhan sistem dan pengguna. Sebagai referensi yang didapat pada tahun 2016, Kharisma D.P mahasiswi program studi Sistem Informasi dalam tugas akhirnya telah membuat dokumen SRS untuk sistem informasi akademik Universitas Ma Chung. Namun, hasil dari dokumen yang dibuat tidak spesifik dan tidak sesuai dengan kebutuhan universitas pada saat itu, sehingga dokumen ini tidak bermanfaat dengan sebagaimana mestinya.

Pada umumnya dan sesuai dengan tahap pengembangan sistem, dokumen SRS disusun saat tahap awal pembangunan sistem akan tetapi pada kondisi yang ada saat ini dokumen SRS disusun ketika sistem telah terbangun dan telah digunakan. Dokumen SRS ini dinilai penting karena macIS akan dikembangkan lebih lanjut dan membantu pihak pengembang sistem 
URL : https://jurnal.machung.ac.id/index.php/kurawal

(developer) dalam membangun macIS yang sesuai dengan kebutuhan universitas saat ini. Pembuatan dokumen SRS akan dilakukan dengan kegiatan pendokumentasian ulang dan melakukan identifikasi kembali terhadap sistem yang sudah digunakan atau terimplementasi yaitu pada macIS. Proses yang terbalik ini dapat dikategorikan dalam kegiatan revaluasi yang artinya adalah penilaian kembali, penilaian terhadap sebuah objek (sistem) untuk meningkatkan dan menjaga kualitas dari sistem yang telah dibangun. Tujuan pembuatan dokumen SRS ini adalah untuk menyesuaikan kebutuhan pengembangan sistem yang berubah sesuai dengan kebutuhan organisasi dan mendokumentasikannya dengan baik.

\section{METODE / ALGORITMA}

\subsection{Alur Penelitian}

Penelitian yang dilakukan untuk menyusun dokumen revaluasi spesifikasi kebutuhan perangkat lunak untuk sistem informasi terintegrasi Universitas Ma Chung diawali dengan merumuskan masalah yang ada. Dalam memahami permasalahan yang terjadi dan bagaimana menyelesaikannya dibutuhkan bimbingan dari expert judgement atau narasumber. Pertama, yang dilakukan adalah dengan merumuskan masalah yang terjadi, dilakukan kegiatan studi literatur guna mengumpulkan informasi, data dari sumber tertulis yang releven dengan topik penelitian. Hal ini bermanfaat juga untuk memperkuat argumentasi dari sumber kepustakaan yang dijadikan sebagai rujukan. Kedua, dalam penelitian perlu ditentukan objek penelitian agar penelitian yang dilakukan terfokus, sesuai dan dapat menyelesaikan permasalahan yang terjadi. Ketiga, ialah menentukan standar penulisan dokumen yang paling sesuai, baru dan memenuhi kebutuhan. Standar penulisan dokumen yang ditentukan adalah yang berstandar internasional, hal ini ditujukan agar dokumen yang disusun terpercaya dan terjamin kualitasnya. Setelah menentukan standar penulisan dokumen, Keempat, dalam penyelesaian masalah atau dalam tahap analisis dibutuhkan sebuah metode yang sesuai dengan studi kasus dan kebutuhan, yang mana metode ini dapat mempermudah kegiatan analisis. Dalam kegiatan analisis dilakukan data gathering atau pengumpulan data serta informasi yang dilakukan dengan beberapa metode yaitu wawancara dan expert judgement. 


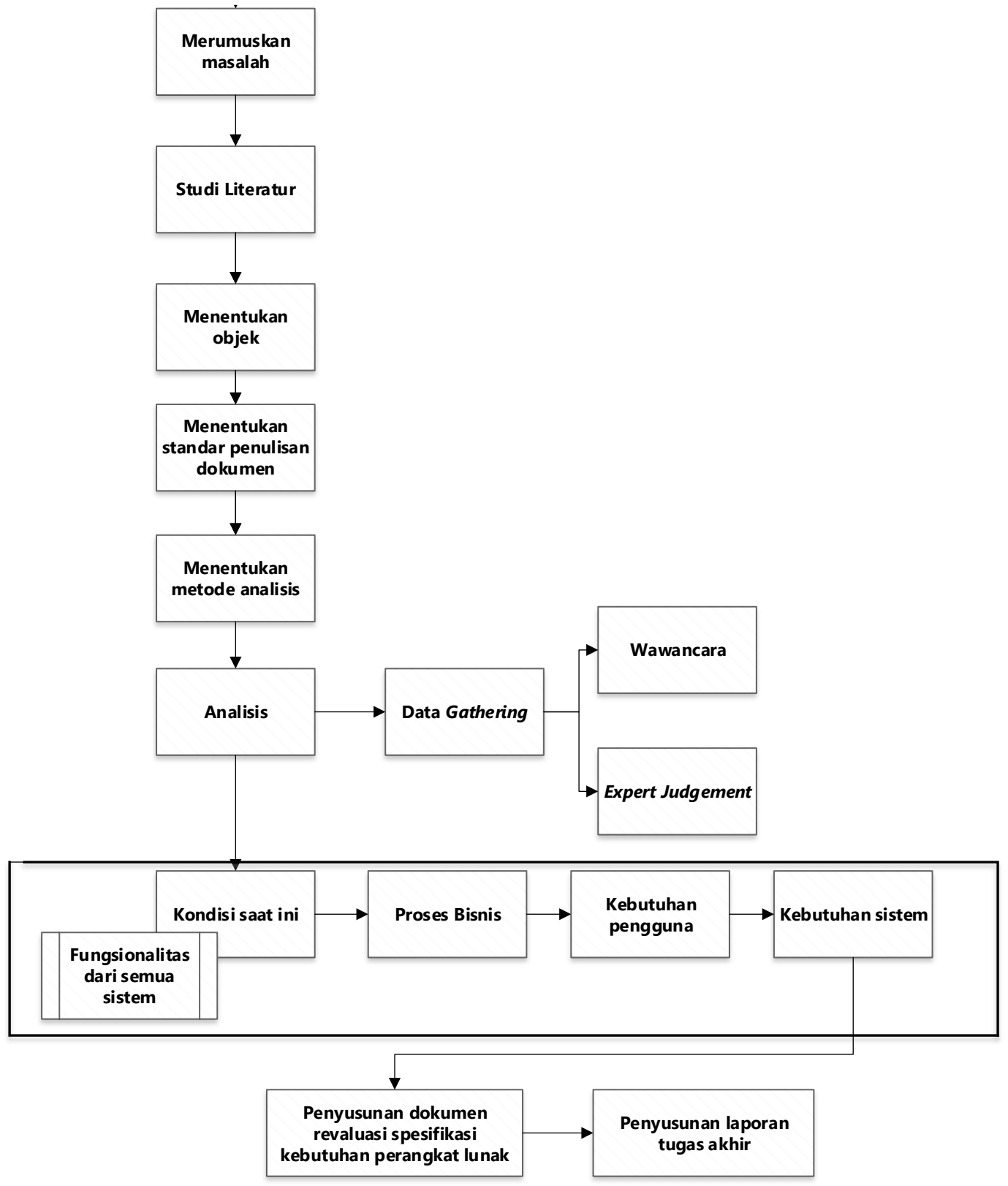

Gambar 1 Alur Penelitian

Kegiatan wawancara akan dilakukan dengan pimpinan UPT SI di Universitas Ma Chung. Dalam kegiatan wawancara akan disusun sejumlah pertanyaan yang diajukan, pengolahan hasil wawancara selanjutnya akan disusun rapi dan dikonfirmasikan kembali keakuratan data dan informasi kepada pihak terkait dengan bukti sebuah tanda tangan. Data gathering yang dilakukan dengan cara expert judgement adalah mengumpulkan pendapat, informasi dari orang-orang yang berpengalaman dibidang yang sesuai dengan topik. Selain hal tersebut, kegiatan expert judgement dilakukan agar penelitian yang dilakukan semakin kritis dan tepat sasaran. Kegiatan analisis dilakukan dengan 
URL : https://jurnal.machung.ac.id/index.php/kurawal

menerapkan beberapa metode diatas untuk mendapatkan informasi dan data terkait dengan kondisi saat ini (objek penelitian) dengan memahami fungsionalitas dari semua sistem yang sedang diterapkan pada Universitas Ma Chung, proses bisnis yang sedang berjalan, kebutuhan pengguna serta kebutuhan sistem sehingga pada tahap akhir dapat disusun sebuah dokumen revaluasi spesifikasi kebutuhan perangkat lunak (SRS) dan laporan tugas akhir. Gambar 1 di atas adalah menunjukkan alur penelitian yang dilakukan.

\subsection{Metode Penulisan Dokumen}

Dokumen SRS dapat disusun dengan berbagai standar yang ada yang dapat dijadikan sebagai acuan, seperti standar keluaran IEEE yaitu ISO/IEC/IEEE 29148-2011 yang merupakan pengganti dari IEEE 830-1998, standar yang dikeluarkan oleh Departemen Pertahanan Amerika Serikat yaitu MIL-STD-298 [4]. Berdasarkan dari dua standar yang dapat digunakan sebagai acuan penulisan dokumen SRS, penulis menentukan untuk menggunakan standar keluaran IEEE yaitu ISO/IEC/IEEE 29148-2011. Hal ini dikarenakan standar ini lebih sesuai untuk diterapkan pada lingkungan pendidikan dibandingkan dengan standar MIL-STD yang secara dasar digunakan untuk standar militer. Selain itu, standar IEEE memiliki kelebihan yaitu struktur templateSRS yang lebih rapi dan mudah untuk dipahami.Outline dari SRS yang akan digunakan ada pada gambar 2, secara garis besar isi dari outline tersebut dapat dijelaskan, yaitu sebagai berikut [5]:

1. Introduction: Menjelaskan mengenai tujuan, ruang lingkup, nama dari sistem, apa yang dapat dilakukan sistem, menjelaskan bagaimana perangkat lunak dapat beroperasi, menjelaskan fungsi utama, menjelaskan karakteristik dari pengguna serta menjelaskan batasan sistem.

2. References: Menuliskan referensi yang digunakan dalam penyusunan dokumen

3. Spesific requirements: Menjelaskan secara detail mengenai persyaratan dari perangkat lunak. Seperti (stimulus) inputan, respon (ouput) dari perangkat lunak serta semua fungsi yang dilakukan oleh sistem

4. Verification: Memberikan pendekatan verifikasi dan metode yang direncanakan untuk memenuhi syarat perangkat lunak

5. Appendices: Menjelaskan asumsi atau perubahan yang dapat mempengaruhi SRS. 
URL : https://jurnal.machung.ac.id/index.php/kurawal

\begin{tabular}{|l|}
\hline 1. Introduction \\
1.1 Purpose \\
1.2 Scope \\
1.3 Product overview \\
1.3.1 Product perspective \\
1.3.2 Product functions \\
1.3.3 User characteristics \\
1.3.4 Limitations \\
1.4 Definitions \\
2. References \\
3. Specific requirements \\
3.1 Extemal interfaces \\
3.2 Functions \\
3.3 Usability Requirements \\
3.4 Performance requirements \\
3.5 Logical database requirements \\
3.6 Design constraints \\
3.7 Software system attributes \\
3.8 Supporting information \\
4. Verification \\
(parallel to subsections in Section 3) \\
5. Appendices \\
5.1 Assumptions and dependencies \\
5.2 Acronyms and abbreviations
\end{tabular}

Gambar 2 Outline Dokumen SRS

\subsection{Metode Analisis}

Metode penelitian pada dasarnya merupakan cara ilmiah untuk mendapatkan data dengan tujuan dan kegunaan tertentu [6]. Metode yang digunakan pada penelitian ini adalah menggunakan metodologi analisis berorientasi obyek yaitu metode penyelesaian masalah dengan menggunakan pendekatan berorientasi obyek[7]. Tujuan dari analisa berorientasi obyek yaitu untuk menentukan kebutuhan pemakai secara akurat. Pendekatan-pendekatan yang dipakai dalam analisa berorientasi obyek antara lain:

1) Pendekatan top-down yaitu memecahkan masalah ke dalam bagian-bagian terkecil/perlevel sehingga mudah untuk diselesaikan.

2) Pendekatan modul yaitu membagi sistem ke dalam modul-modul yang dapat beroperasi tanpa ketergantungan.

3) Penggunaan alat-alat bantu dalam bentuk grafik dan teks sehingga mudah untuk dimengerti serta dikoreksi bila terjadi perubahan. [8] 
URL : https://jurnal.machung.ac.id/index.php/kurawal

Pendekatan dalam analisa berorientasi obyek dilengkapi dengan alat-alat dan teknikteknik yang dibutuhkan dalam pengembangan sistem, sehingga akhir dari sistem yang dikembangkan akan didapatkan sistem yang terdefinisi dengan baik dan jelas. Pendekatan yang digunakan pada penelitian ini adalah menggunakan alat bantu dalam bentuk grafik dan teks dengan memanfaatkan alat dan teknik yang dibutuhkan dalam pengembangan sistem. Hal ini ditujukan agar proses yang dilakukan mudah untuk dipahami serta sistem dapat terdefinisi dengan sangat baik dan jelas.

\section{HASIL DAN PEMBAHASAN}

Hasil dari kegiatan data gathering untuk memperoleh informasi mengenai kondisi saat ini (obyek penelitian) adalah sistem terintegrasi yang telah dikembangkan oleh UPT SI diantaranya yaitu macIS PMB Online, macIS Registrasi Mahasiswa, macIs Sipenmaru, macIs Akademik, macIS Manajemen Akademik, macIS Keuangan Mahasiswa, macIS Dosen, macIs Mahasiswa, macIS Manajemen Kampus, macIs Eksekutif, macIS kurikulum dan macIS control. Gambar 3 adalah gambaran sistem yang telah terintegrasi satu dengan yang lainnya:

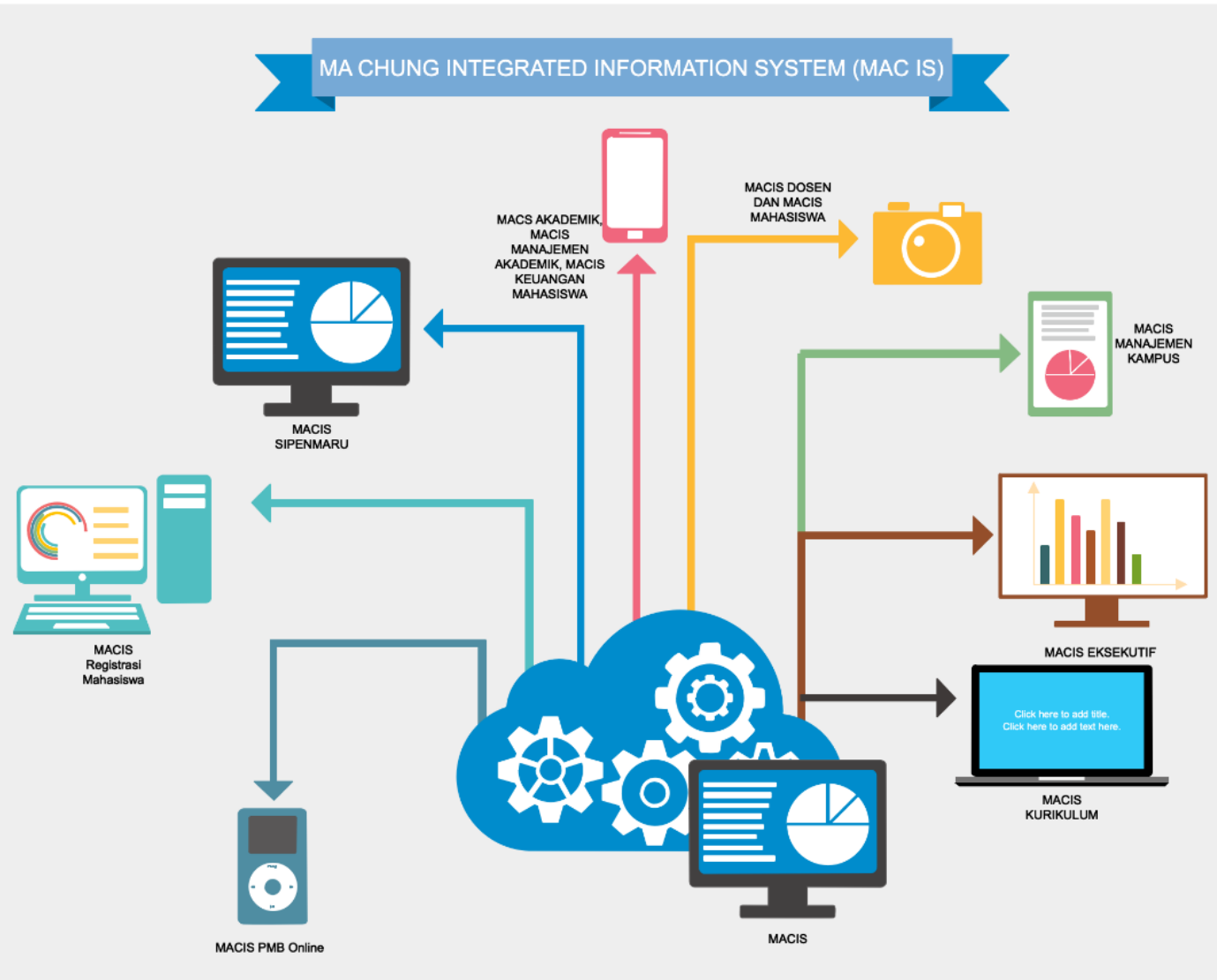

Gambar 3 Sistem Terintegrasi Saat Ini 
Berikut adalah sebagian hasil dari penyusunan dokumen SRS untuk masing-masing sistem:

1. macIS PMB (Penerimaan Mahasiswa Baru)

Sistem dapat berjalan pada platform atau sistem operasi apa saja yang mendukung aplikasi berbasis web. Sistem dapat dijalankan oleh admin pada device memiliki koneksi internet. Pengguna untuk macIS PMB adalah siswa-siswi lulusan SMA/SMK sederajat di seluruh Indonesia sebagai calon pendaftar di Universitas Ma Chung. Kegiatan pengguna hanya terbatas pada mengisi formulir, melakukan konfirmasi aktivasi serta mengakses login sistem registrasi mahasiswa. MACIS PMB hanya hanya digunakan oleh calon pendaftar.

2. macIS Registrasi

Sistem dapat menyediakan halaman untuk calon mahasiswa baru dapat mengunggah berkas persyarata pendaftaran serta melihat informasi status pendaftaran. Sistem bersifat selfservice.Pengguna untuk macIS Registrasi mahasiswa adalah calon mahasiswa baru Universitas Ma Chung. MACIS Registrasi mahasiswa hanya dapat diakses oleh calon mahasiswa yang telah melakukan konfirmasi atau aktivasi sehingga memiliki username dan password.

\section{3. macIS SIPENMARU}

Sistem dpat bekerja sebagai control untuk mencapai keberhasilan dari seluruh proses bisnis dalam kegiatan pendaftaran, registrasi hingga penerimaan mahasiswa baru. Pengguna untuk macIS SIPENMARU adalah Biro Kerjasama dan Pemasaran Universitas Ma Chung bagian Pemasaran dan Pendaftaran Mahasiswa Baru. macIS SIPENAMRU hanya dapat diakses oleh Biro Kerjasama dan Pemasaran serta hanya mengelola data pendaftaran, registrasi hingga pembuatan SKR (Surat Keputusan Rektor).

4. macIS Akademik

Sistem dapat dapat melakukan penjadwalan perkuliahan, plotting dosen pembimbing akademik, layanan Kartu Rencana Studi (KRS), mastering data serta kalkulasi absensi dan nilai. Pengolahan data transaksi yang ada pada macIS Akademik akan ditampilkan atau dimonitoring pada macIS Manajemen akademik. Pengguna untuk macIS Akademik adalah sekretariat fakultas. Penjadwalan dan plotting dosen pembimbing dapat dilakukan oleh staff bagian penjadwalan.

5. macIS Manajemen Akademik

Sistem dapat open privilege untuk mengatur periode KRS, Validasi KRS, input nilai dan absensi. Monitoring kegiatan perkuliahan yaitu melihat status kalkulasi dosen, validasi KRS 
URL : https://jurnal.machung.ac.id/index.php/kurawal

mahasiswa, mengolah data mahasiswa transfer dan melakukan generate NIM.Pengguna untuk macIS Manajemen Akademik adalah Biro Pendidikan bagian adminitrasi akademik.Seluruh fungsi yang tersedia dalam sistem dapat diakses oleh staff Biro Pendidikan bagian administrasi akademik tergantung pada pembagian tugas dan tanggung jawab dari masing-masing staff.

6. macIS Keuangan Mahasiswa

Sistem dapat digunakan untuk membuat data tagihan, pembayaran, tunggakan maupun dispensasi keuangan bagi mahasiswa.Sistem dapat digunakan untuk membuka akses macIS agar mahasiswa dapat melakukan KRS dan mengikuti Ujian Akhir Semester (UAS). Sistem dapat digunakan untuk manajemen dan pengelolaan adminitrasi keuangan mahasiswa Biro Sumber Daya dan Keuangan bagian Keuangan Mahasiswa dengan salah satu hak akses yaitu hanya dapat membuka akses KRS jika mahasiswa telah melakukan pembayaran tagihan keuangan pada semester terkait.

7. macIS Dosen

Sistem dapat digunakan untuk kegiatan input dan kalkulasi nilai, presensi dan rekap presensi mahasiswa hingga monitoring status dan validasi KRS Mahasiswa.Hasil inputan nilai dan presensi yang telah dilakukan dosen pengampu mata kuliah akan terupdate secara langsung dalam waktu sehari setelah waktu input, sehingga mahasiswa dapat melihat informasi nilai dan presensi pada macIS Mahasiswa.Beberapa menu dalam macIS Dosen terkait dengan menu yang ada pada macIS Akademik dan Manajemen Akademik.Pengguna untuk macIS Dosen adalah seluruh dosen pengajar.Seluruh dosen dapat melakukan input nilai dan presensi apabila periode input nilai dan presensi telah dibuka. Kegiatan validasi KRS hanya dapat dilakukan oleh dosen pembimbing akademik.

8. macIS Mahasiswa

Sistem dapat menyediakan informasi kegiatan perkuliahan yaitu nilai, presensi, IPK, tanggungan keuangan, jumlah total pembayaran keuangan, melakukan input point keaktifan, melakukan KRS online serta mengisi angket evaluasi perkuliahan. Pengguna untuk macIS Mahasiswa adalah mahasiswa status aktif maupun cuti. macIS Mahasiswa hanya dapat digunakan oleh mahasiswa Universitas Ma Chung, serta menu KRS online dapat diakses oleh mahasiswa yang telah lunas melakukan pembayaran keuangan pada semester terkait. 
URL : https://jurnal.machung.ac.id/index.php/kurawal

9. macIS Manajemen Kampus

Sistem dapat digunakan untuk inventarisasi mulai dari kegiatan pendataan, pengelolaan, maintenance hingga pelaporan aset, baik aset tetap maupun aset tak berwujud yang dimiliki oleh Universitas Ma Chung.Pengguna untuk macIS Manajemen Aset adalah Biro Sumber Daya dan Keuangan bagian Pengelolaan dan Pemeliharaan Aset.Biro Sumber Daya dan Keuangan bagian Pengelolaan dan Pemeliharaan Aset dapat melakukan pengelolaan terhadap seluruh aset yang telah dimiliki oleh Universitas Ma Chung.

10. macIS Eksekutif

Sistem dapat digunakan untuk menghubungkan keseluruhan proses bisnis mulai dari calon mahasiswa mendaftar di Univeristas Ma Chung sampai mahasiswa menjadi alumni. Serta untuk monitoring dan pelaporan seluruh kegiatan akademik. Kepala program studi, pimpinan akademik, semua pimpinan dalam unit kampus.Tidak ada keahlian khusus yang harus dimiliki oleh pengguna, pengguna hanya diharapkan mengerti untuk proses perencanaan dan pengambilan keputusan.Kepala program studi hanya dapat melihat data dan melakukan persetujuan tanpa dapat melakukan perubahan dan penghapusan data. 


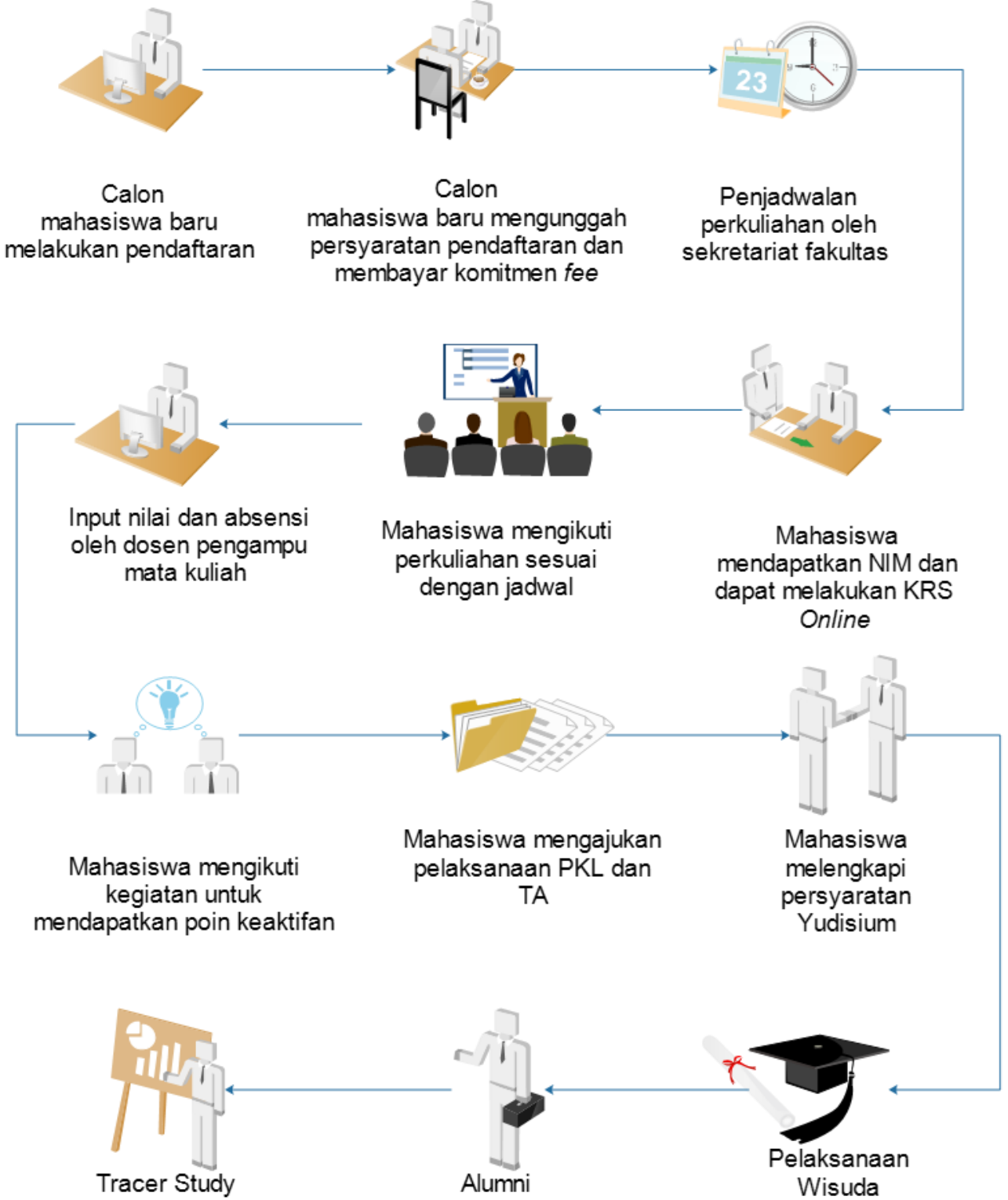

Gambar 4 Proses Bisnis General Kegiatan Akademik

11. macIS Kurikulum

Sistem dapat digunakan untuk manajemen kurikulum, konversi melakukan perubahan dan simulasi untuk program studi menyediakan informasi kegiatan perkuliahan yaitu nilai, presensi, IPK, tanggungan keuangan, jumlah total pembayaran keuangan, melakukan input point keaktifan, melakukan KRS online serta mengisi angket evaluasi perkuliahan. Pengguna untuk macIS Kurikulum adalah kepala program studi dan Bidang Akademik bagian kurikulum. Keahlian khusus yang harus dimiliki oleh pengguna adalah pengguna dapat memiliki kemampuan perencanaan yang strategis bagi program studinya dan memiliki kepekaan 
URL : https://jurnal.machung.ac.id/index.php/kurawal

terhadap perubahan ilmu pengetahuan yang dinamis. Kaprodi dapat melakukan mapping mata kuliah berdasarkan dengan kurikulum yang telah disepakati oleh seluruh pihak terkait.

Jumlah dokumen SRS yang disusun adalah sebanyak 11 dokumen sesuai dengan jumlah sistem yang ada. SRS ini dibuat berdasarkan objek yang ada yaitu macIS, masing-masing macIS didefinisikan sesuai standar penulisan dokumen SRS yaitu ISO/IEC/IEEE 29148-2011 dan memenuhi seluruh tahapan yang ada. Dalam dokumen SRS tahap spesific requirements sub tahap functions khusunya functional requirements disusun dengan berdasarkan proses bisnis yang terjadi. Tabel 1 merupakan contoh dari tabel functional requirementsuntuk macIS Registrasi.

Tabel 1 Functional requirementsuntuk macIS Registrasi

\begin{tabular}{|c|c|c|c|}
\hline \multirow[t]{2}{*}{ No } & \multirow{2}{*}{ Deskripsi Kebutuhan } & \multicolumn{2}{|c|}{ Fungsional } \\
\hline & & Pengguna & Sistem \\
\hline 1 & $\begin{array}{l}\text { Pengguna dapat mengakses sistem dengan menginputkan username dan } \\
\text { password yang telah diterima setalah melakukan konfirmasi } \\
\text { pembayaran }\end{array}$ & $\checkmark$ & \\
\hline 2 & $\begin{array}{l}\text { Pengguna dapat memperoleh panduan mengakses sistem yang mudah } \\
\text { untuk dipahami }\end{array}$ & $\checkmark$ & \\
\hline 3 & $\begin{array}{l}\text { Sistem dapat menampilkan halaman tutorial penggunaan sistem berupa } \\
\text { video }\end{array}$ & & $\checkmark$ \\
\hline 4 & $\begin{array}{l}\begin{array}{l}\text { Pengguna dapat memperoleh informasi umum mengenai status } \\
\text { pendaftarannya }\end{array} \\
\end{array}$ & $\checkmark$ & \\
\hline 5 & $\begin{array}{l}\text { Pengguna dapat mengelola data pribadi untuk kelengkapan dari proses } \\
\text { registrasi dengan mengubah atau memperbaharui biodata yang telah } \\
\text { diinputkan sebelumnya }\end{array}$ & $\checkmark$ & \\
\hline 6 & $\begin{array}{l}\text { Sistem dapat menampilkan data pribadi pendaftar berdasarkan dengan } \\
\text { hasil yang telah diinputkan di website pendaftaran pada saat tahap } \\
\text { pendaftaran online. }\end{array}$ & & $\checkmark$ \\
\hline 7 & $\begin{array}{l}\text { Pengguna dapat melihat daftar dokumen pendaftaran yang harus } \\
\text { dilengkapi dalam proses registrasi }\end{array}$ & $\checkmark$ & \\
\hline 8 & Sistem dapat menampilkan daftar kelengkapan dokumen pendaftran & & $\checkmark$ \\
\hline 9 & Pengguna dapat mengisi formulir pendaftaran bagian unggah dokumen & $\checkmark$ & \\
\hline 10 & $\begin{array}{l}\text { Sistem dapat menyimpan hasil inputan formulir pendaftaran unggah } \\
\text { dokumen }\end{array}$ & & $\checkmark$ \\
\hline 11 & $\begin{array}{l}\text { Sistem dapat menampilkan halaman formulir pendaftaran unggah } \\
\text { dokumen }\end{array}$ & & $\checkmark$ \\
\hline 12 & Pengguna dapat memilih berkas atau dokumen yang akan diunggah & $\checkmark$ & \\
\hline 13 & Sistem dapat menyimpan data unggahan & & $\checkmark$ \\
\hline 14 & $\begin{array}{l}\text { Sistem dapat menampilkan tabel daftar dokumen yang sudah diunggah } \\
\text { sesuai dengan persyaratan }\end{array}$ & & $\checkmark$ \\
\hline
\end{tabular}


URL : https://jurnal.machung.ac.id/index.php/kurawal

\section{KESIMPULAN}

Dokumen revaluasi spesifikasi kebutuhan perangkat lunak menggunakan standar penulisan dokumen SRS yaitu ISO/IEC/IEEE 29148-2011 dan menggunakan metode analisis kebutuhan berorientasi objek telah tersusun dengan cukup baik. Parameter yang digunakan untuk menilai hasil dokumen adalah berdasarkan dari pembuatan seluruh tahapan dalam penyusunan yang sesuai dengan outline SRS. Kegiatan analisis dan identifikasi dalam penyusunan kebutuhan pengguna, kebutuhan sistem untuk tabel kebutuhan fungsional dilakukan berdasarkan dari masing-masing proses bisnis yang ada.Saran untuk pembuatan dokumen spesifikasi kebutuhan perangkat lunak selanjutnya adalah agar lebih didetailkan lagi dan menggunakan bahasa yang tidak ambigu atau menimbulkan banyak tafsiran, tidak berbelit-belit, fokus dan konsisten. Serta proses yang dilakukan dalam analisis kebutuhan hendaknya dilakukan dengan bertahap, detail dan terjadwal.

\section{REFERENSI}

[1] Finandhita Alif, Teknik Informatika UNIKOM, Proses Pembangunan Perangkat Lunak , Repository UNIKOM

[2] Jogiyanto. 2001. Analisis \& Desain Sistem Informasi: Pendekatan Terstruktur Teori dan Praktek Aplikasi Bisnis. Andi, Yogyakarta

[3] Pengajarku, 10 Juli 2019, Analisis Sistem:Pengertian,Tujuan, Fungsi, Tahapan dan Contohnya, https://pengajar.co.id/analisis-sistem-pengertian-tujuan-fungsi-tahapan-dancontohnya/

[4] Prakoso Bimo, 2018, Komparasi Kualitas Standar Dokumen Software Requirement Specification (SRS): MIL-STD-498 DAN IEEE 830-1998, Tugas Akhir, Universitas Islam Indonesia. Yogyakarta

[5] Organisation Internationale de Normalisation (ISO). ISO/IEC/IEEE 29148:2011. Systems and software engineering - Life cycle processes -- Requirements engineering.2011.

[6] Sugiyono, 2013, Metodelogi Penelitian Kuantitatif, Kualitatif Dan R\&D. (Bandung: ALFABETA)

[7] Mahdiana Deni, 2011, Analisa dan Rancang Sistem Informasi Pengadaan Barang Dengan Metodologi Berorientasi Obyek: Studi Kasus PT. Liga Indonesia, Jurnal Telematika MKOM, Vol.3 No.2, September 2011 
URL : https://jurnal.machung.ac.id/index.php/kurawal

[8] Whitten, Jeffery L., Lonnie D. Bentley, Kevin C. Dittman, 2004, System Analisis and Design Methods. 6th ed. New York: McGraw-Hill 